\title{
Factors Affecting Accessibility and Utilization of Condom for HIV Prevention among Students in University of Calabar Community, Nigeria
}

\author{
Osonwa Kalu O ${ }^{1}$, Eko Jimmy E. ${ }^{2}$, Abeshi, S. E. ${ }^{3}$, Offiong Dominic A. ${ }^{2}$ \\ 1. Department of Sociology, Faculty of Social Sciences, University of Calabar, Calabar, Nigeria. \\ 2. Department of Public Health, College of Medical Sciences, University of Calabar, Calabar, Nigeria. \\ 3. Department of Obstetrics \& Gynecology, University of Calabar, Calabar, Nigeria \\ Corresponding authors address: emekusi@yahoo.com
}

Accepted: August 14, 2013 Published: Sep 06, 2013

Doi:10.5296/ijld.v3i4.4243 URL: http://dx.doi.org/10.5296/ijld.v3i4.4243

\begin{abstract}
This study was done to identify the factors affecting the accessibility and utilization of condom for HIV prevention among students in University of Calabar Community, Nigeria. The multi-stage sampling technique was used to select a sample of five hundred (500) students from the University Community. A questionnaire which comprised of four sections with fifty items were administered to the respondents. Data collected were analyzed using frequency tables, graphs, means, standard deviations and the statistical package for social science (SPSS). The result shows that all respondents who have heard of HIV/AIDS have also seen a condom, with television (34.3\%) as their major source of information. More than half of the respondents $(53.9 \%)$ reported not using condom in their last sexual encounter. It is recommended among others that campaigns against HIV/AIDS should provide a forum where students will be cleared of certain misconceptions about the disease and the use of condom.
\end{abstract}

Keywords: HIV/AIDS, Condom, Prevention, University students.

\section{Introduction}

\subsection{Background of the study}

HIV/AIDS remains a threat to population health in Nigeria; it continues to strain the struggling health system and reverse many developmental gains of the recent past. Nigeria carries the second heaviest burden of HIV in Africa and has an expanding population of People Living with HIV (PLHIV) (NACA, 2012). Despite challenges in scaling up access, institutional reforms and political commitment to tackle the diseases, the country has seen more citizens placed on life saving medication. For the twenty six year period dated 1986 till December 2011, that AIDS was first reported in Nigeria, 3,459,363 people now live with HIV and an estimated 1,449,166 require ARV. 388,864 new infections occurred in the year ended 2011 and records show 217,148 AIDS related deaths (Nigerian Federal Ministry of Health, 2010). Between 1991 and 2001, Nigeria witnessed an increase in the prevalence of HIV in the country. The first case of AIDS in Nigeria was reported in 1986 thereby establishing the presence of the epidemic in the country. Consequently, and in line with guidelines from the 
World Health Organization (WHO), the government adopted ANC sentinel surveillance as the system for assessing the epidemic. The national HIV Sero-prevalence level, obtained from sentinel surveys of antenatal care attendees, increased from 1.8 percent in 1991 to 5.8 percent in 2001 and then declined to 5.0 percent in 2003 and further to 4.4 percent in 2005 . This was followed by a rise to 4.6 percent in 2008 and then a recent decline to 4.1 percent in 2010 (NACA, 2012). An analys is of the 2010 prevalence rates in the country's six geopolitical zones shows that the highest concentration is in the North Central Zone (7.5\%) and the lowest prevalence rate is in the North Western Zone, at 2.1\% (Nigerian Federal Ministry of Health, 2010). There are also differences between and within urban and rural areas with prevalence figures in urban areas varying between $2.7 \%$ and $18.0 \%$, while that of the rural area range from $0.7 \%$ to $21.3 \%$. Socio-demographic differences in the HIV prevalence are also observable with women, youths, and people with low level of formal education being worst affected by the epidemic. Infection rates among young people aged 15-19 put at 3.3\%; 20-24 at $4.6 \%$ and 25-29 at 5.6\% are considered very high and a key national strategy in the current national strategic framework is to direct focused national HIV prevention efforts to address this trend (UNFPA, 2011).

Nigeria has been steadfast in its commitments to strengthen its response to the HIV and AIDS epidemic through the implementation of multi-sectoral comprehensive intervention programs. These programs include, but not limited to, education on the 'ABCs' of prevention (abstinence/delayed sexual initiation, being safer by being faithful to one's partner/reducing the number of sexual partners, and correct and consistent condom use), treatment and care of sexually transmitted infections, voluntary counseling and testing services, prevention of mother-to-child transmission, harm reduction, safe blood supplies and medical injections, and addressing discrimination and stigmatization.

Condom promotion and distribution programmes have grown significantly since the beginning of the AIDS epidemic. Global practices show that the male latex and female condoms are the most efficient and available technology to reduce the sexual transmission of HIV and other sexually transmitted infections (UNFPA, 2011). Condom use is more likely when people can access them at no cost or at greatly subsidized prices. Effective condom promotion targets not only the general population, but also people at higher risk of HIV exposure especially young people which are the focus of this study. Condoms have encouraged safer sexual behaviour more generally. Recent analysis of the AIDS epidemic in Uganda has confirmed that increased condom use, in conjunction with a delay in the age of first sexual intercourse and a reduction of sexual partners, was an important factor in the decline of HIV prevalence in the 1990s. Thailand's efforts to de-stigmatize condoms and its targeted condom promotion for sex workers and their clients dramatically reduced HIV infections in these populations and helped reduce the spread of the epidemic to the general population. A similar policy in Cambodia has helped stabilize national prevalence, while substantially decreasing prevalence among sex workers (UNFPA, 2011). In addition, Brazil's early and vigorous condom promotion among the general population and vulnerable groups has successfully contributed to sustained control of the epidemic. According to UNAIDS, an estimated 13 billion condoms per year are needed to help halt the spread of HIV and other sexually transmitted infections. While the search for new preventive technologies such as HIV vaccines and microbicides continues to make progress, condom use will remain the key preventive tool for many years to come (UNFPA, 2011).

Indubitably, about two-third of Nigerian university students comprises of young people aged 15-29 years which constitute the high risk group for HIV infection in Nigeria. A recent trend analysis by Global AIDS Response Country Progress Report (GARPR) revealed that, HIV prevalence among young people aged $15-24$ years is $4.3 \%$ in $2005,4.2 \%$ in 2008 and 
$4.2 \%$ in 2010 (NACA, 2012). Higher institution students are usually confined in separate environs, away from their parents, don't know where to go to get the service they need and don't have the money as well as the time to go outside to get Sexual and Reproductive Health services. Moreover, Higher Education students have serious concerns in areas like love, relationship and physical health problems; academic and school related problems; and serious psychological concerns (DKT Ethiopia \& Timret Lehiwot Ethiopia, 2009). As most of the students are young people with few or no life experience and information especially on sexual and reproductive health (SRH) issues, many of them are vulnerable to various problems including unwanted pregnancies, unsafe abortion, sexually transmitted infections including HIV/AIDS, gender based violence as well as sexual violence and risky sexual practices in and around the various campuses of the universities. Despite the existence of risky sexual behavior, there is no adequate RH-focused intervention in most of the universities in Nigeria and the issue is complicated by the fact that the problem goes beyond SRH issues and has social, political and economic dimensions which require multi-sectoral response.

Several factors affect young adults' correct and consistent use of condoms. In Angola among 15-24 year olds, consistent condom use was positively associated with higher levels of education, with belief that condoms did not diminish sexual pleasure, believing that condoms were safe (among males) and having multiple partners (among males) and negatively associated with being married or being in a cohabiting re lationship, and equating condom use with lack of trust (among females) (Prata, Vahidnia \& Fraser, 2005). Other external factors that could influence condom use are accessibility to health facilities, reliable and correct reproductive health information, operating hours and issues of confidentiality and availability of condoms (Barker \& Rich, 1992). Type of sexual partner, whether casual or regular, and socio-economic status of the family to which the young adult belongs, have been found to influence condom use (Douthwaite \& Saroun, 2006; Calazans, Araujo, Venturi \& Franca, 2003)).

\subsection{Statement of the Problem}

A recent analysis on HIV epidemic by UNAIDS revealed that, more than 34 million people now live with HIV/AIDS worldwide and about 3.3 million of the $m$ are under the age of 15. In 2011, an estimated 2.5 million people were newly infected with HIV and nearly 7,000 people contract HIV— nearly 300 every hour daily (UNAIDS, 2012). Sub-Saharan Africa still bears an inordinate share of the global HIV burden. According to UNAIDS, more than two-thirds (69 percent) of all people living with HIV, 23.5 million, live in sub-Saharan Africa and an estimated 1.8 million people in the region became newly infected. The most recent HIV Sero-prevalence figure represents about 3.5 million people infected with HIV, ranking Nigeria third among the countries with the highest HIV/AIDS burden in the world, next only to India and South Africa. Although the Nigerian median pre valence of HIV has taken a downward turn in recent years, the absolute number of people living with HIV has increased by almost half a million people in three years and AIDS related mortality has also slightly increased in the same time period to about 217,148 annual deaths attributed to AIDS (NACA,2012).

University students in Nigeria are usually a conglomerate of young people with divergent culture and religion of multi-lingual origin. Influx of young people from HIV high risk zones across the country indicates that students who are not infected with HIV or from low HIV risk zones are susceptible to becoming infected with HIV which may eventually lead to an increase in the number of newly infected people. However, several studies have reported high knowledge of condom with low access and usage (Alvarez, Villarruel, Zhou \& Galle gos, 2010; Katikiro \& Njau, 2012). Some authors have argued that many factors affects availability, accessibility and usage of condom among young people in different part of the world 
(Maticka-Tyndale, 2012; Chimbindi, McGrath, Herbst, San Tint \& Newell, 2010; Adedimej, Heard, Odutolu \& Omololu, 2012; Orubuloye, 2004), but very few data have been found on university students which is obviously one of the high risk population for HIV infection. Hence, the necessity of carrying out this research.

\subsection{Objective of Study}

The objective of the study is to identify factors affecting the accessibility and utilization of condoms in relation to HIV prevention in University of Calabar community, Nigeria.

\subsection{Significance of the study}

This study will provide a baseline survey for further research on similar studies. It will also aid policy makers to formulate a workable framework that will enable young people have access to condom and promote its use. Data generated from this study will be informative to Non-governmental and governmental organizations and will enhance the adoption of a sustainable approach or strategy on condom programs in order to meet the need of the high risk group for HIV infection and mitigate the scourge simultaneously. Management of higher institutions in Nigeria and beyond would also see the need to collaborate with implementation agencies to moot a symposium on issues that affect condom access and use among students at regular interval.

\subsection{Theoretical Framework}

The Health Belief Model is most widely used researched models which originated in the 1950's as a way to understand health-seeking behaviors (Rosenstock, 1974). It has also been used both to explain change and maintenance of health related behaviors and as a guiding framework for health behavior interventions. For instance, several studies have reported that sexually active university students indulge in having unprotected sexual intercourse with their partners. This shows that these students have low risk perception of being infected with HIV/STD (Perceived Susceptibility) which will definitely expose them to several health problems such as HIV/STD infections, unwanted pregnancy, unsafe abortion and other sexual and reproductive health problems (Perceived Severity). Students who acquire and use condom correctly and consistently are always protected from sexual health problems and consequently live a normal healthy life (Perceived Benefit). 
Figure 1: Operational description of the Health Belief Model.

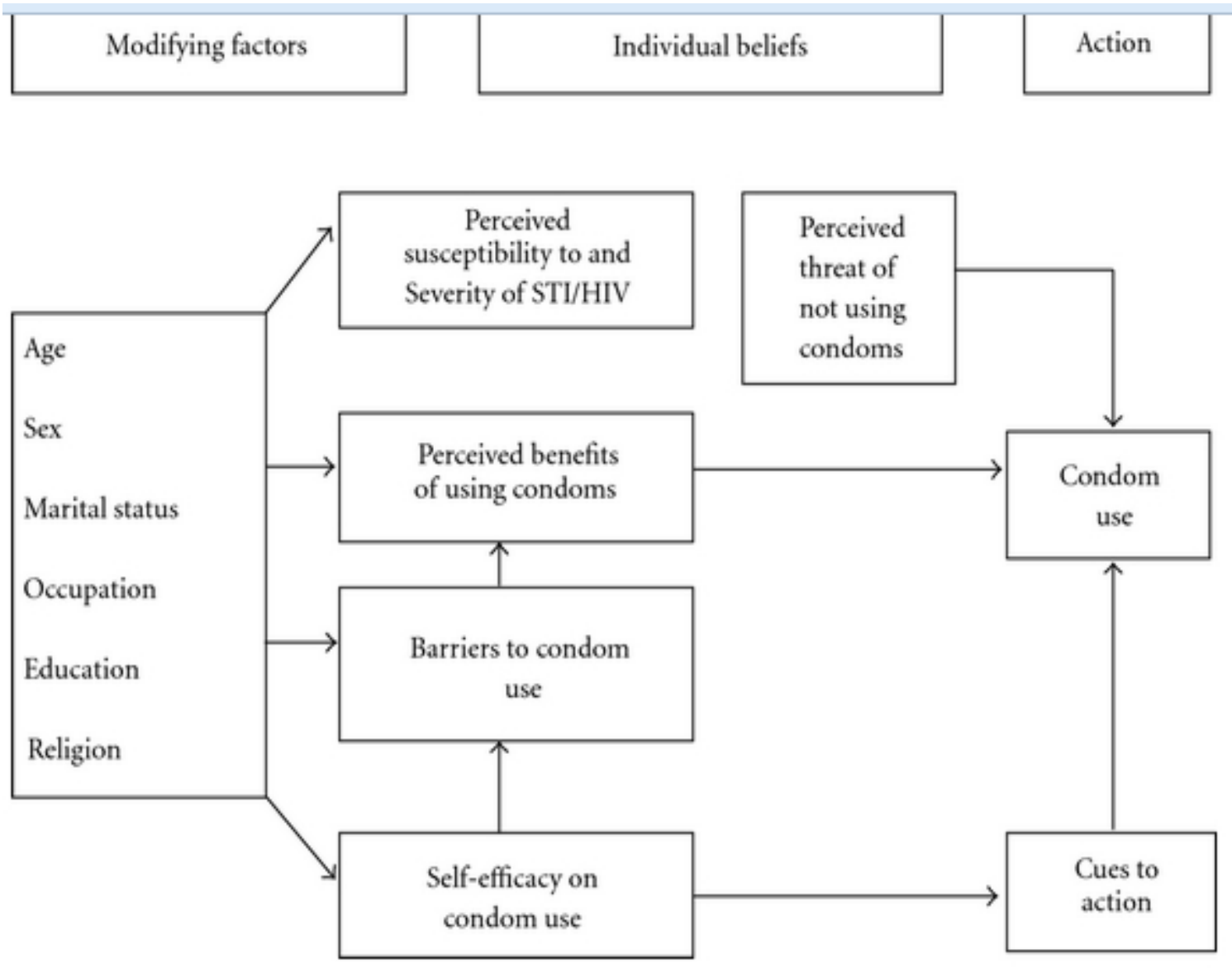

Source: (Katikiro \& Njau, 2012)

If students are aware of the benefits of using a condom and the perceived consequences of not using a condom, it will serve as a buffer in outweighing factors such as condom reduces sexual pleasure, condom burst/tear during usage, partners' disapproval of condom use, condom encourages promiscuity, religion imposition on condom use etc. that are considered as barrier to high condom use (Perceived Barriers). Electronic media, seminar/workshops on condom education, advertisement in billboards, posters, calendars, mortality rate from AIDS and symptoms of full blown AIDS should serve as reminders for students to adopt a positive behavior towards condom access and utilization (Cues to Action). Individuals who access and use condom correctly and consistently with confidence should anchor some seminars/workshops on condom education to encourage and also build self-confidence in others who tend to shy away from using condom because of some myths or misconception (Self Efficacy). It is believed that university students who use the Health Belief Model will adopt the desired behavioral change towards accessing and using condom for HIV prevention.

\section{Methodology}

\subsection{Study Setting}

The study area is University of Calabar Community. University of Calabar - also known as

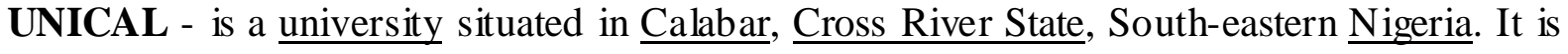


one of Nigerian's second generation universities. The University of Calabar was a campus of the University of Nigeria until 1975. It was established by decree to fulfill this traditional mandate, its motto "Knowled ge for Service". The male students are known as Malabites, while the female students are Malabresses. The male hostel is called Malabor. The institution has about 15 faculties, 90 departments and about 500 programmes (i.e. Undergraduate \& Post graduates programmes). The population comprises of students, academic and non-academic staffs. One health center, one teaching hospital, two notable research institution (Step-B project and Canadian Cross River State Health Surveillance System), Administrative block, Afrihub, students and staff accommodation, lecture halls are notable infrastructure found in the institution.

\subsection{Study Population}

The study population comprised of students (Undergraduates and Postgraduates) in University of Calabar community, Cross River State, Nigeria.

\subsection{Study Design}

A descriptive cross-sectional survey was employed to identify factors affecting accessibility and utilization of condom for HIV prevention in University of Calabar community between April 1-26, 2013 and both quantitative and qualitative data was generated.

\subsection{Sampling Procedure}

Multi-stage sampling technique was employed to select participants who gave their consent to participate in this study. The procedure is described as follows:

1. Using the sampling frame of all faculties in University of Calabar, Five faculties were selected using systematic random sampling technique. The faculties included; Faculty of Allied Medical Science, Faculty of Arts, Faculty of Sciences, Faculty of Social Sciences and Faculty of Education.

2. In each selected faculty, 2 departments were selected using simple random sampling technique giving a total of $2 \times 5=10$ departments employed in the study. These department were Public health, Radiography, Theatre Arts, Religion and Philosophy, Geology, Botany, Public Administration, political science, Education Biology and Education Administration.

3. In each department, 40 students were randomly selected giving a total of $40 \times 10=400$ students employed in the study.

4. To account for attrition problem, the sample was increased to 500 which became the actual sample size for the study.

\subsection{Data Collection}

Both quantitative and qualitative data were generated using a structured questionnaire from respondents that gave their consent to participate in the study. The questionnaire was self-administered to respondents and tested prior to use. The questionnaire was compartmentalized into 4 sections with about 50 items. The questions were on socio-demographic data of respondents, knowledge of HIV/AIDS infection, knowledge of condom, accessibility and utilization of condom. Selected final year students were trained and employed to collect data for this study.

\subsection{Data Analysis}

The questionnaires were manually sorted out and analyze using Statistical Package for Social Science (SPSS, version 13.0). Data was summarized using frequency tables, graphs, means and standard deviations.

\subsection{Ethical Consideration}

Informed consent was duly sought from respondents. Assurance and adherence of confidentiality of information elicited was maintained throughout the study. Participation in the study was on voluntary basis. 


\section{Macrothink Mnstitutem}

\section{Results}

Out of 500 questionnaires that were distributed, 420 questionnaires were returned and analyzed giving an acceptable response rate of $84 \%$. Nearly half of the respondents 209 (49.8\%) were within the age bracket of 20-24 with a mean age of $24.8 \pm 4.2$ std deviation. A reasonable proportion of the respondents were females 230 (54.8\%), Christians 407 (96.9\%), single 355 (84.5\%), undergraduates 302 (71.9\%), 200 level students $112(37.1 \%)$ and not working 344 (81.9\%). Most of the respondent domicile off campus $303(72.1 \%)$ with their parents 134 (44.2\%). However, about $81(26.7 \%)$ of the respondents reported living alone. A minute proportion of the working class students were civil servant 35 (46.1\%).

Table 1: Socio-Demographic Data of Respondents $(n=420)$

\begin{tabular}{|lll|}
\hline VARIABLES & FREQUENCY & PERCENTAGE \\
\hline Ages in years & 52 & 12.4 \\
\hline $\mathbf{1 5 - 1 9}$ & 209 & 49.8 \\
\hline $\mathbf{2 0 - 2 4}$ & 105 & 25.0 \\
\hline $\mathbf{2 5 - 2 9}$ & 37 & 8.8 \\
\hline $\mathbf{3 0 - 3 4}$ & 10 & 2.3 \\
\hline $\mathbf{3 5 - 3 9}$ & 3 & 0.7 \\
\hline $\mathbf{4 0 - 4 4}$ & 4 & 1.0 \\
\hline $\mathbf{4 5 - 4 9}$ & 0 & 0.0 \\
\hline$>\mathbf{5 0}$ & & \\
\hline Place of Residence & 117 & 27.9 \\
\hline On campus & 303 & 72.1 \\
\hline Off campus & \\
\hline If off campus, who do you live with? & $(\mathrm{n}=303)$ & 44.2 \\
\hline Parents & 134 & 26.7 \\
\hline Live alone & 81 & 7.5 \\
\hline Guardian & 23 & 5.9 \\
\hline Friend & 18 & 11.9 \\
\hline Roommate & 36 & 3.6 \\
\hline Others & 11 & \\
\hline Sex & & 45.2 \\
\hline Males & 190 & 54.8 \\
\hline Females & 230 & \\
\hline Religion & & 96.9 \\
\hline Christianity & 1.4 \\
\hline Islam & 6 & 1.7 \\
\hline Traditional religion & 7 & \\
\hline Marital status & & 14.3 \\
\hline Married & 60 & 84.5 \\
\hline Single & 355 & - \\
\hline Separated & - & 1.2 \\
\hline Widowed & - & \\
\hline Co-habiting & 5 & \\
\hline Programme & 65.5 \\
\hline Unde rgraduate & & \\
\hline Post-graduate & & \\
\hline & & \\
\hline
\end{tabular}




\section{MlMacrothink}

Inte rnational Journal of Learning \& Development

ISSN 2164-4063

2013, Vol. 3, No. 4

\begin{tabular}{|lll|}
\hline Sandwich & 53 & 12.6 \\
\hline If undergraduate what level? $(\mathrm{n}=302)$ & & 14.9 \\
\hline $\mathbf{1 0 0}$ level & 45 & 37.1 \\
\hline 200 level & 112 & 24.5 \\
\hline 300 level & 74 & 23.5 \\
\hline 400 level \& above & 71 & \\
\hline Are you working and school at the same time? & 18.1 \\
\hline Yes & 76 & 81.9 \\
\hline No & 344 & 46.1 \\
\hline Occupation & & 19.7 \\
\hline Civil servant & 35 & 7.9 \\
\hline Teaching & 15 & 14.5 \\
\hline Hair Dressing & 6 & 11.8 \\
\hline Farming & 11 & \\
\hline Others & 9 & \\
\hline
\end{tabular}

In table 2, virtually all respondents reported to have heard of HIV/AIDS infectious disease 420 $(100 \%)$ with media as their major source of information on HIV i.e. television $155(34.3 \%)$ followed by HIV/AIDS campaigns $83(18.4 \%)$ then, radio $79(17.5 \%)$. Most respondents claimed not to have known anyone infected with HIV 312 (74.3\%) but were knowledgeable that HIV can be passed from one person to another $370(87.0 \%)$ and healthy looking people can be HIV positive 381 (90.7\%). While most respondents believed that HIV can be contracted via blood 287 (68.3\%), semen 293 (69.8\%), giving blood 220 (52.4\%), having a blood test 198 $(47.1 \%)$ and sharing a needle with someone who is HIV positive $280(66.7 \%)$, others believed that HIV cannot be contracted via sweat $230(54.8 \%)$, tears $203(48.3 \%)$, saliva $280(66.7 \%)$, urine 198 (47.1\%), insect bites 235 (55.9\%), communion cup 256 (60.9\%), shaking hands with someone who is HIV positive 310 (73.8\%), kissing an infected person with HIV 120 (28.6\%), hugging 277 (65.9\%), sharing smoke with an HIV patient $286(68.1 \%)$, eating food prepared by an infected person $290(69.0 \%)$, using same toilet as someone who is HIV positive 210 (50.0\%) and drinking from same glass as someone who is HIV positive 330 (78.6\%). Only 200 (47.6\%) respondents could clearly state the difference between HIV and AIDS. Almost half of the respondents $(41.2 \%)$ were not sure whether HIV can be cured or not, though $169(40.2 \%)$ respondents believed HIV cannot be cured. About 171 (40.7\%) respondents expressed their unassurance whether AIDS has a vaccine or not, but $158(37.6 \%)$ respondents agreed that there is a vaccine to prevent HIV infection. Majority of the respondents 337 (80.2\%) expressed their willingness to undergo HIV test. Respondents agreed that staying faithful to one partner 338 (80.5\%), use condom correctly and consistently 339 (80.7\%), avoid multiple sex partners 332 $(79.0 \%)$ and abstaining from sex (335 79.8\%) were ways one can avoid being infected with HIV infection.

Table 2: Knowledge/A wareness of HIV Infection $(n=420)$

\begin{tabular}{|lll|}
\hline VARIABLES & FREQUENCY & PERCENTAGE \\
\hline Ever heard of HIV/AIDS before & & 100 \\
\hline Yes & 420 & - \\
\hline No & - & \\
\hline Source of Information $(\mathrm{n}=452)$ & & 34.3 \\
\hline Tele vision & 155 & 17.5 \\
\hline Radio & 79 & 10.6 \\
\hline Billboard/posters & 48 & 8.6 \\
\hline Friends & 39 & \\
\hline
\end{tabular}




\section{Macrothink Mnstitute ${ }^{\mathrm{m}}$}

Inte rnational Journal of Learning \& Development

ISSN 2164-4063

2013, Vol. 3, No. 4

\begin{tabular}{|c|c|c|}
\hline Husband & 1 & 0.2 \\
\hline HIV/AIDS campaign & 83 & 18.4 \\
\hline Health workers & 37 & 8.2 \\
\hline Others & 10 & 2.2 \\
\hline \multicolumn{3}{|c|}{ Differences between HIV and AIDS } \\
\hline Correct response & 200 & 47.6 \\
\hline Incorrect response & 220 & 52.4 \\
\hline \multicolumn{3}{|c|}{ Knowledge of someone that is HIV positive } \\
\hline Yes & 108 & 25.7 \\
\hline No & 312 & 74.3 \\
\hline \multicolumn{3}{|c|}{ Can HIV be passed from one person to another } \\
\hline Yes & 370 & 87.0 \\
\hline No & 50 & 13.0 \\
\hline \multicolumn{3}{|c|}{ Can a healthy looking person be HIV positive } \\
\hline Yes & 381 & 90.7 \\
\hline No & 39 & 9.3 \\
\hline \multicolumn{3}{|l|}{ Can HIV be cured } \\
\hline Yes & 78 & 18.6 \\
\hline No & 169 & 40.2 \\
\hline Not sure & 173 & 41.2 \\
\hline \multicolumn{3}{|c|}{ Is there a vaccine for AIDS } \\
\hline Yes & 171 & 40.7 \\
\hline No & 122 & 29.0 \\
\hline Not sure & 127 & 30.2 \\
\hline \multicolumn{3}{|c|}{ Is there a vaccine to prevent HIV Infection } \\
\hline Yes & 158 & 37.6 \\
\hline No & 139 & 33.1 \\
\hline Not sure & 123 & 29.3 \\
\hline \multicolumn{3}{|c|}{ Would you be willing to have an HIV test } \\
\hline Yes & 337 & 80.2 \\
\hline No & 53 & 12.6 \\
\hline Not sure & 30 & 7.1 \\
\hline \multicolumn{3}{|c|}{ Ways a person can avoid getting HIV infection } \\
\hline \multicolumn{3}{|c|}{ A) Staying with one faithful partner } \\
\hline Yes & 338 & 80.5 \\
\hline No & 82 & 19.5 \\
\hline \multicolumn{3}{|c|}{$\begin{array}{l}\text { B) Using condom correctly and } \\
\text { consistently }\end{array}$} \\
\hline Yes & 339 & 80.7 \\
\hline No & 81 & 19.3 \\
\hline \multicolumn{3}{|c|}{ C) Avoid multiple sex partners } \\
\hline Yes & 332 & 79.0 \\
\hline No & 88 & 20.9 \\
\hline \multicolumn{3}{|c|}{ D) Abstaining from sex } \\
\hline Yes & 335 & 79.8 \\
\hline No & 85 & 20.2 \\
\hline
\end{tabular}




\section{Macrothink $\Lambda$ Institute ${ }^{\mathrm{m}}$}

Inte rnational Journal of Learning \& Development

ISSN 2164-4063

2013, Vol. 3, No. 4

\begin{tabular}{|c|c|c|c|c|}
\hline \multirow[t]{2}{*}{ Variable } & \multicolumn{4}{|c|}{ Frequency (percentage) } \\
\hline & Agreed & Disagreed & Not sure & $\begin{array}{l}\text { Don't } \\
\text { know }\end{array}$ \\
\hline Blood & $287(68.3)$ & $60(14.3)$ & $40(9.5)$ & $33(7.9)$ \\
\hline Sweat & $100(23.8)$ & $230(54.8)$ & $30(7.1)$ & $\begin{array}{l}60 \\
(14.3)\end{array}$ \\
\hline Tears & $116(27.6)$ & $203(48.3)$ & $50(11.9)$ & $\begin{array}{l}51 \\
(12.1)\end{array}$ \\
\hline Semen & $293(69.8)$ & $15(3.6)$ & $107(25.5)$ & $5(1.2)$ \\
\hline Saliva & $103(24.5)$ & $280(66.7)$ & $20(4.8)$ & $17(4.0)$ \\
\hline Urine & $105(25.0)$ & $198(47.1)$ & $95(22.6)$ & $22(5.2)$ \\
\hline Insect bites & $100(23.8)$ & $235(55.9)$ & $70(16.7)$ & $15(3.6)$ \\
\hline Communion cup & $107(25.5)$ & $256(60.9)$ & $57(13.6)$ & - \\
\hline Giving blood & $220(52.4)$ & $90(21.4)$ & $95(22.6)$ & $15(3.6)$ \\
\hline Having a blood test & $198(47.1)$ & $105(25.0)$ & $95(22.6)$ & $22(5.2)$ \\
\hline $\begin{array}{l}\text { Shaking hands with someone who is } \\
\text { HIV positive }\end{array}$ & $20(4.8)$ & $310(73.8)$ & $55(13.1)$ & $35(8.3)$ \\
\hline Kissing someone who is $\mathrm{HIV}$ positive & $111(26.4)$ & $120(28.6)$ & $102(24.3)$ & $\begin{array}{l}87 \\
(20.7)\end{array}$ \\
\hline Hugging someone who is HIV positive & $50(11.9)$ & $277(65.9)$ & $70(16.7)$ & $23(5.5)$ \\
\hline $\begin{array}{l}\text { Eating food prepared by someone who } \\
\text { is HIV positive }\end{array}$ & $60(14.3)$ & $290(69.0)$ & $66(15.7)$ & $4(1.0)$ \\
\hline $\begin{array}{l}\text { Sharing a s moke with someone who is } \\
\text { HIV positive }\end{array}$ & $90(21.4)$ & $286(68.1)$ & $34(8.1)$ & $10(2.4)$ \\
\hline $\begin{array}{l}\text { Sharing a needle with someone who is } \\
\text { HIV positive }\end{array}$ & $280(66.7)$ & $20(4.8)$ & $103(24.5)$ & $17(4.0)$ \\
\hline $\begin{array}{l}\text { Using the same toilet seat as someone } \\
\text { who is HIV positive }\end{array}$ & $198(47.1)$ & $210(50.0)$ & $10(2.4)$ & $2(0.5)$ \\
\hline $\begin{array}{l}\text { Drinking from the same glass as } \\
\text { someone with HIV }\end{array}$ & $44(10.5)$ & $330(78.6)$ & $40(9.5)$ & $6(1.4)$ \\
\hline
\end{tabular}

In table 3, about 417 (99.3\%) of the respondents claimed to have heard of condom before and $380(90.5 \%)$ said they have seen how a condom looks like. Male condom was the predominant type of condom seen by the respondents 254 (60.5\%), though 160 (38.1\%) of the respondents believed to have seen both male and female condoms. The major source of information reported by the respondents is through seminar/workshops 133 (31.7\%), followed by schools $123(23.9 \%)$. As reported by the respondents, condoms are used majorly for prevention of HIV \& STDs $228(44.8 \%)$ while the remaining respondents believed condoms are used as contraceptives. More than half of the respondents believed that condom use is for everyone 254 $(60.5 \%)$ and both the man and woman should come to a consensus before using it $238(56.7 \%)$. Based on knowledge of types of condom, Rough Rider recorded highest 151 (38.5\%). However, $100(25.5 \%)$ respondents have no knowledge of the types of condoms available.

Table 3: Knowledge of Condom among Respondents $(n=420)$

\begin{tabular}{|lll|}
\hline VARIABLE & FREQUENCY & PERCENTAGE \\
\hline Ever heard of condom before & & 99.3 \\
\hline Yes & 417 & 0.7 \\
\hline No & 3 & \\
\hline Source of Information & & \\
\hline
\end{tabular}




\section{Macrothink Mnstitutem}

Inte rnational Journal of Learning \& Development

ISSN 2164-4063

2013, Vol. 3, No. 4

\begin{tabular}{|c|c|c|}
\hline Parents & 38 & 9.0 \\
\hline School & 123 & 29.3 \\
\hline Lecturer & 15 & 3.6 \\
\hline Poster/handbills & 49 & 11.7 \\
\hline Seminar/workshop & 133 & 31.7 \\
\hline Church & 5 & 1.2 \\
\hline Friend & 43 & 10.2 \\
\hline Others & 14 & 3.3 \\
\hline \multicolumn{3}{|l|}{ Ever seen a condom before } \\
\hline Yes & 380 & 90.5 \\
\hline No & 40 & 9.5 \\
\hline \multicolumn{3}{|l|}{ What type of condom } \\
\hline Male condom & 254 & 60.5 \\
\hline Female condom & 6 & 1.4 \\
\hline Both & 160 & 38.1 \\
\hline \multicolumn{3}{|l|}{ Uses of condom $(n=509)$} \\
\hline Prevention of HIV \& STDs & 228 & 44.8 \\
\hline Prevention of unwanted pregnancy & 136 & 26.7 \\
\hline Child Spacing & 66 & 13.0 \\
\hline Limit family size & 56 & 11.0 \\
\hline No idea & 23 & 4.5 \\
\hline \multicolumn{3}{|l|}{ Group of people meant to use condom } \\
\hline Drivers & 3 & 0.7 \\
\hline University students & 43 & 10.2 \\
\hline Commercial sex workers & 38 & 9.0 \\
\hline Older adults & 17 & 4.0 \\
\hline Youths & 45 & 10.7 \\
\hline Everyone & 254 & 60.5 \\
\hline No idea & 20 & 4.8 \\
\hline \multicolumn{3}{|c|}{ Knowledge of types of condom $(n=392)$} \\
\hline Rough rider & 151 & 38.5 \\
\hline Durex & 66 & 16.8 \\
\hline Sensation & 48 & 12.2 \\
\hline Hiowt trust & 3 & 0.8 \\
\hline Does not know & 100 & 25.5 \\
\hline Others & 24 & 6.1 \\
\hline \multicolumn{3}{|c|}{ Decider of condom use in a sexual relationship } \\
\hline Man & 53 & 12.6 \\
\hline Woman & 58 & 13.8 \\
\hline Both & 238 & 56.7 \\
\hline No idea & 71 & 16.9 \\
\hline
\end{tabular}

In table 4, most respondents reported not having a condom 291 (69.3\%) with sexually inactivity $95(32.6 \%)$, religious barrier $72(24.7 \%)$ and parent's disapproval 60 (20.6\%) being their top three reasons for not having a condom. About $247(62.5 \%)$ of the respondents had no knowledge of where condoms can be given for free, but 148 (37.5\%) said that condoms are given freely in places such as during world HIV/AIDS campaign days, hospitals, health 


\section{1) Macrothink}

Inte rnational Journal of Learning \& Development

ISSN 2164-4063

2013, Vol. 3, No. 4

centers, heart-to-heart center, WHO \& SFH offices, women development center, Girls power Initiative and AIDS strikers club in Calabar. Most respondents reported that condoms can be easily accessible in chemist 261 (67.2\%) and hospitals 95 (24.5\%). A substantial proportion of the respondents $220(57.7 \%)$ reported that they have never attended a health education programme on condom where procedures for condom use are being demonstrated. However, about 161 respondents said they have attended a health education on condom use before and was anchored by organization such as SACA, WHO, GHAIN, UNICEF, USAID, progressive youth club etc. Based on utilization of condom, half of the respondents reported to have used a condom before $193(50.8 \%)$ and male condoms recorded high usage 168 (87.0\%). Surprisingly, about $115(59.6 \%)$ respondents clearly stated that they did not use a condom in their last sexual encounter with reasons such as 'I trust my partner $54(29.2 \%)$ and partner's refusal to use a condom $21(11.4 \%)$, though a large proportion of the respondents $55(29.7 \%)$ had no reason for not using a condom in their last sexual encounter. A handful of the respondents $78(40.4 \%)$ who reported using a condom in their last sexual encounter gave a major reason for usage such as for protection from contracting HIV \& STDs 86 (54.4\%). More than half of the respondents $(74.1 \%)$ reported that they don't enjoy having sex with condom; reason being that condom majorly reduces sexual satisfaction $86(60.1 \%)$. About 144 respondents agreed that there were times they want to use a condom but couldn't use it majorly because condom was not available $53(36.8 \%)$. Three hundred and seventeen respondent agreed to recommend condom use to both married and unmarried people 182 (57.4\%) for them to be majorly protected from unwanted pregnancy, STDs, HIV/AIDS. Few respondents said they would not recommend condom use to others largely because it will encourage promiscuity $51(43.2 \%)$ and extra-marital affairs $43(36.4 \%)$. Nearly two-third of the respondents said they have discussed about condom use with their partners and about $214(62.9 \%)$ were willing to accept condom use.

Table 4: Accessibility and Utilization of Condom among Respondents

\section{VARIABLES $\quad$ FREQUENCY $\quad$ PERCENTAGE}

\begin{tabular}{|l|l|l|}
\hline Currently having a condom $(\mathrm{n}=420)$ & 30.7 \\
\hline Yes & 129 & 69.3 \\
\hline No & 291 & 24.7 \\
\hline Reasons for not having a condom $(\mathrm{n}=291)$ & \multicolumn{2}{l|}{} \\
\hline $\begin{array}{l}\text { Religious belief against condom } \\
\text { use }\end{array}$ & 72 & 20.6 \\
\hline Parent's Disapproval & 60 & 0.3 \\
\hline Peer Influence/stigma & 1 & 32.6 \\
\hline Not sexually active & 95 & 1.0 \\
\hline Don't know where to buy it & 3 & 2.7 \\
\hline Regarded as a prostitute & 8 & 11.6 \\
\hline No reason & 34 & 6.2 \\
\hline Others reasons & 18 & \\
\hline Knowledge of places where condoms can be given for free $(\mathrm{n}=395)$ & 37.5 \\
\hline Yes & 148 & 62.5 \\
\hline No & 247 & 67.2 \\
\hline Knowledge of places where condoms can be bought $(\mathrm{n}=388)$ & 24.5 \\
\hline Che mist & 261 & 1.5 \\
\hline Hospitalclinic & 95 & 6.7 \\
\hline Market & 6 & \\
\hline No idea & 26 & \\
\hline
\end{tabular}




\section{Macrothink}

Inte rnational Journal of Learning \& Development

ISSN 2164-4063

2013, Vol. 3, No. 4

\begin{tabular}{|c|c|c|c|c|c|}
\hline & & & $\begin{array}{l}\text { Ever attended a health educati } \\
(\mathrm{n}=381)\end{array}$ & cond & ondon \\
\hline & & & Yes & 161 & 42.3 \\
\hline & & & No & 220 & 57.7 \\
\hline Ever used a condo $m$ before $(n=3$ & & & Ever used a condom before $(n=$ & & \\
\hline & & & Yes & 193 & 50.8 \\
\hline & & & No & 187 & 49.2 \\
\hline & & & Type of condom used $(n=193)$ & & \\
\hline & & & Male condom & 168 & 87.0 \\
\hline & & & Female condom & 7 & 3.6 \\
\hline & & & Both & 18 & 9.3 \\
\hline Used condom in last sexual enco & & & Used condom in last sexual enc & $\operatorname{er}(n=1$ & \\
\hline & & & Yes & 78 & 40.4 \\
\hline & & & No & 115 & 59.6 \\
\hline Reasons for using condom $(n=1$ & & & Reasons for using condom $(\mathrm{n}=$ & & \\
\hline & & & Prevent unwanted pregnancy & 59 & 37.3 \\
\hline & & & Protect against HIV \& STDs & 86 & 54.4 \\
\hline & & & Child spacing & 6 & 3.8 \\
\hline & & & Reduce family size & - & - \\
\hline & & & Have multiple sex partners & 7 & 4.4 \\
\hline & & & Other reasons & - & - \\
\hline Reasons for not using a condom & & & Reasons for not using a condon & 185) & \\
\hline & & & No reason & 55 & 29.7 \\
\hline & & & Want to have a child & 6 & 3.2 \\
\hline & & & Partner's refusal & 21 & 11.4 \\
\hline & & & Religion disapproval & 7 & 3.8 \\
\hline & & & Trust my partners & 54 & 29.2 \\
\hline & & & Others & 42 & 22.7 \\
\hline Usually enjoy having sex with c & & & Usually enjoy having sex with & $\mathrm{m}(\mathrm{n}=$ & \\
\hline & & & Yes & 50 & 25.9 \\
\hline & & & No & 143 & 74.1 \\
\hline Reasons for not enjoying sex wi & & & Reasons for not enjoying sex $\mathrm{w}$ & ndom & \\
\hline & & & Reduces sexual satisfaction & 86 & 60.1 \\
\hline & & & Usually burst during sex & 34 & 23.8 \\
\hline & & & Reduces sexual urge & 22 & 15.4 \\
\hline & & & Others & 1 & 0.7 \\
\hline Were there times you wanted to & & & Were there times you wanted to & a cond & $70)$ \\
\hline & & & Yes & 144 & 53.3 \\
\hline & & & No & 126 & 46.7 \\
\hline Reasons for not using a condom & & & Reasons for not using a condon & 144) & \\
\hline & & & No reason & 7 & 4.9 \\
\hline & & & Partner's refusal & 46 & 31.9 \\
\hline & & & Condom not available & 53 & 36.8 \\
\hline & & & No money to buy a condom & 3 & 2.1 \\
\hline & & & Condom I had finished & 32 & 22.2 \\
\hline & & & Others & 3 & 2.1 \\
\hline
\end{tabular}




\begin{tabular}{|l|l|l|}
\hline Yes & 317 & 84.1 \\
\hline No & 60 & 15.9 \\
\hline Group of people you would like to recommend condom use to (n=317) \\
\hline Married people & 26 & 8.2 \\
\hline Unmarried people & 102 & 32.2 \\
\hline Both married and unmarried & 182 & 57.4 \\
\hline No idea & 7 & 2.2 \\
\hline Reasons for recommending condom use (n=317) & 78.5 \\
\hline $\begin{array}{l}\text { Prevent unwanted pregnancy, } \\
\text { STDs \& HIV/AIDS }\end{array}$ & 249 & 18.0 \\
\hline $\begin{array}{l}\text { Those having multiple sex } \\
\text { partners }\end{array}$ & 57 & 3.5 \\
\hline Other reasons & 11 & 43.2 \\
\hline Reasons for not recommending condom use (n=118) & 36.4 \\
\hline Encourage promiscuity & 51 & 18.6 \\
\hline Encourage extramarital affairs & 43 & - \\
\hline Religion barrier r & 22 & 1.7 \\
\hline No reason & - & 60.3 \\
\hline Other reasons & 2 & 39.7 \\
\hline Ever discussed about condom with your partner before (n=340) \\
\hline Yes & 205 & 62.9 \\
\hline No & 135 & 37.1 \\
\hline Partner's willingness to accept condom use (n=340) \\
\hline Willing to accept condom use & 214 & \\
\hline Unwilling to accept condom use & 126 \\
\hline
\end{tabular}

\section{Discussion}

\subsection{Knowledge/Awareness of HIV/AIDS}

In this study, university students exhibited high level of awareness about HIV/AIDS infection. This finding is similar with other studies carried out in Nigeria where high HIV/AIDS knowledge was equally recorded (Adepoju, 2006; Dibua \& Agweda, 2010; Olaitan, 2007). Virtually all respondents (100\%) have heard of HIV/AIDS infection with the media (TV-34.3\%; Radio-17.5\%) as their major source of information; though about 83 (18.4\%) respondents heard of HIV/AIDS during routine HIV/AIDS campaigns. This shows that effective HIV/AIDS messages could reach a conglomerate of university students via the media and yearly HIV/AIDS campaigns where a lot of these university students partake in the road work exercise. This result is consistent with a study carried out in Wuhan, China among university students (Albrektsson, Alm, Tan \& Andersson, 2009). Despite the high level of HIV/AIDS knowledge, most respondents $220(52.4 \%)$ weren't able to differentiate between HIV and AIDS. This group of university students may probably be young secondary school leavers who had less exposure to HIV/AIDS information. A reasonable proportion of the respondents $312(74.3 \%)$ reported they don't know someone that is infected with HIV. This agrees with the popular adage in Nigeria that says "HIV no de show for face". This means that people could be infected with HIV but nobody may know they are infected probably because of fear of stigmatization or the infection is still at its early stage. Most respondents (87.0\%) believed that HIV can passed from one person to another mainly through blood (68.3\%), semen $(69.8 \%)$, blood test $(52.4 \%)$, having a blood test $(47.1 \%)$ and sharing a needle with someone that is HIV positive (66.7\%); these respondents equally reported that HIV cannot be passed 
from person-to-person through tears $(48.3 \%)$, saliva $(66.7 \%)$, sweat $(54.8 \%)$, urine $(47.1 \%)$, insect bites (55.9\%), communion cup (60.9\%), Kissing (28.6\%), hugging (65.9\%), shaking of hands $(73.8 \%)$ and other causal contacts. This finding corroborates with a cross-sectional study carried out among students in Semey, Kazakhstan (Hansson et al, 2008). Attempt must be made to correct these misconceptions during HIV campaigns as this may hamper control measures. While $41.2 \%$ of the respondents were uncertain whether AIDS has cure or not, about $40.7 \%$ of the respondents believed AIDS has a vaccine and $37.6 \%$ said there is a vaccine to prevent HIV infection. This results from the numerous misbelieves carried by media houses that some individuals have discovered the cure for HIV/AIDS or vaccine to prevent HIV infection. Hence, the public health system have a responsibility to debunk these misconceptions. Majority of university student (80.2\%) reported they would be willing to undergo HIV test. High knowledge level of HIV was also shown when most students believed that HIV infection could be avoided by staying with one faithful partner, using condom correctly and consistently, avoiding multiple sex partners and abstaining from sex.

\subsection{Knowledge of Condom}

Nearly all the respondents $(99.3 \%)$ claimed to have heard of condom majorly in seminars/workshops (31.7\%). Some students said schools $(29.3 \%)$ were their source of information about condom. About $90.5 \%$ respondents reported to have seen a condom, predominantly the male latex condom $(60.5 \%)$. Only $38.1 \%$ have seen both the female and male latex condom. The male latex condom is widely advertised during seminar and workshops, and is also easily available, affordable and accessible. Very few respondents (1.4\%) reported seeing the female condom. Based on condom use, $44.8 \%$ said condoms are mainly used for prevention of HIV \& STDs, whereas the remaining $55.2 \%$ believed that condoms are used as contraceptives. This shows that condom is a multi-purpose device that can be used for various purposes as earlier pointed by the respondents. This study corroborates with a study carried out in Calabar, Nigeria, where $62.3 \%$ of the respondents believed that the latex condom can be used as a preventive measure (Phillip-Ephiram, Udonwa, Gyuse, Peters \& Anyanechi, 2010). More than half of the respondents (60.5\%) believed that everyone is meant to use condom probably because everyone is substantially at risk of HIV infection. Respondents also had adequate knowledge of available types of condoms as Rough Rider (38.5\%) recorded highest. Though, $25.5 \%$ had no knowled ge of the available types of condom. Gold circle type of condom was also predominantly known among respondents. About $56.7 \%$ subscribed to the fact that both partners must reach a consensus before condomcan be used in a heterosexual relationship. While $13.8 \%$ females said that women are the sole decider of condom use, $12.6 \%$ said it's the man who should decide. This finding disagrees with a study carried out by (Chimbindi et al, 2010) stating that "condom is a male-determine method-it is the man who decides whether or not to used a condom".

\subsection{Accessibility and Utilization of Condom}

More than half $(69.3 \%)$ of the respondents reported not having a condom. Most reasons given were not sexually active at the moment $(32.6 \%)$, religious belief against condom use (24.7\%) and parent's disapproval (20.6\%). Students should be told the risk of gallivanting around without a condom for protection. Religious organizations should be incorporated in routine HIV prevention campaigns. Parents should be educated on the perceived benefits on why they should encourage their subjects to have a condom and perceived severity of not having a condom. While, $62.5 \%$ of the respondents have no idea where condoms can be given for free, as few as $37.5 \%$ said condoms can be given freely in places such as hospitals, health centers, Organizations, HIV/AIDS campaign office and d uring world HIV/AIDS day. Notably, no where around the university environment is condom distributed freely except for the health 
center where students visit only when they are ill. Hence, condoms should be distributed freely at strate gic places within the university environs to enhance improve accessibility to condom that will progressively motivate utilization. About $67.2 \%$ reported that condoms can be bought in chemist and $24.5 \%$ said it can be bought in the hospitals. Since condoms are made for health purposes, respondents believed that condoms should be readily available in health outlets such as chemist and health facilities. More than half of the respondents $(57.7 \%)$ reported that they haven't attended any health education program on condom where procedures for condom use are being demonstrated. However, only $42.3 \%$ said they have attended a health education program where procedures for condom use are being demonstrated majorly anchored by WHO, SACA, GHAIN, UNICEF and other non-organization. This shows that programs on condom use should be intensified in Nigerian universities so that students have an idea on how to use a condom. Only $49.2 \%$ of the respondents reported that they have used a condom before in their lifetime predominantly the male latex condom (87.0\%). Surprisingly, only $46.1 \%$ reported to have used a condom in their last sexual encounter. Reasons for usage were predominantly to protect against HIV \& STDs (54.4\%) and prevent unwanted pregnancy (37.3\%). This finding supports a community based cross-sectional descriptive study in Ethiopia (Belachew, 2002). As large as $53.9 \%$ of the respondents said they did not use condom in their last sexual encounter because they trust their partners (29.2\%) and partners refused to use it $(11.4 \%)$; though most students had no reason for not using a condom (29.7\%). Findings agreed with a study carried out by Bedimo et al, 1998. A substantial proportion of the respondents $(74.1 \%)$ complained not enjoying sex with condom with predominant reasons such as condom reduces sexual satisfaction $(60.1 \%)$, condom usually burst during sex $(23.8 \%)$ and condom reduces sexual urge $(15.4 \%)$. This finding agreed with a study carried out by (Phillip-Ephraim et al, 2010). Education and awareness of condom use should be intensified to debunk these misconceptions among university students to enhance the achievement of MDG target by 2015. More than half of the respondents (53.3\%) said that there were times they wanted to use a condom but couldn't use it, reasons being that condom was not available (36.8\%) and cogently followed by partner's refusal to use a condom (31.9\%). The government and non-governmental organization should enforce massive condom distribution among Nigerian universities. This strategy will help ameliorate the scourge to the bearest minimum. Three hundred and seventeen respondents $(84.1 \%)$ agreed to recommend condom used to both the married and the unmarried people $(57.4 \%)$ for them to be protected majorly from HIV \& STDs and unwanted pregnancy $(78.5 \%)$. Out of 377 respondents, $60(15.9 \%)$ respondents said they would not recommend condom use to others because it will encourage promiscuity $(43.2 \%)$ and extra-marital affairs (36.4\%). Also, 18.6\% said their religious belief is against condom use. This finding corroborated with a study carried out by Belachew, 2002. Slightly, more than half of the respondents $60.3 \%$ claimed to have talk to their partner about condom use and $62.9 \%$ were willing to use it. Massive distribution of condoms, enlightenment campaigns and symposiums, additional condom distribution centers should be made available were the suggestions given by respondents to improve condom use among university students.

\section{Conclusion And Recommendation}

This study revealed a high awareness level of HIV infection among university students and low prevalence of condom accessibility and utilization. Factors affecting accessibility of condom in this study includes; Parent's disapproval, religion barriers, fear of stigma, lack of knowledge of where to get it free, and low risk perception of HIV infection. Factors affecting utilization includes; unavailability of condom, low risk perception of being infected with STDs and HIV, partner's refusal, myths and misconception about condom, religion barrier, beliefs that its use will encourage promiscuity and extramarital affairs. Based on these findings, the following recommendations are made: 
1. Condoms should be massively distributed to university students at strategic positions to reach out to students who domicile within and outside campus.

2. Periodic symposiums especially on condom use should be part of the university semester plan.

3. Advertisement on media and billboard should be enforced to continue to remind students on the need to develop a positive attitude towards condom use for posterity sake.

4.

Campaigns against HIV/AIDS should provide a forum where students will be cleared of certain misconceptions about the disease and condom use.

\section{REFERENCES}

[1.] Adedimej A, Heard N, Odutolu O, Omololu O. (2012): Social factors, social support and condom use Behaviour among young urban slum inhabitants in Southwest Nigeria. http//www.hsph.havard.edu/takemi/files/2012/10/Rp226.pdf..

[2] Adepoju JA (2006): Knowledge of HIV/AIDS among nurses in South-west Nigeria. ABNF $J$ fall; 17 (4): 137-42.

[3] Albrektsson M, Alm L, Tan X, Andersson R (2009): HIV/AIDS Awareness, Attitude and Risk Behaviour among university students in Wuhan, China. Open AIDS Journal. 3:55-62.

[4] Alvarez C., Villarruel A. M., Zhou Y, Gallegos E. (2010): Predictors of Condom Use among Mexican Adolescents Res Theory Nurs Pract. 24 (3): 187-194.

[5] Barker GK, Rich S. Influences on adolescent sexuality in Nigeria and Kenya: findings from recent focus-group discussions. Stud Fam Plann. 1992; 23:199-210.

[6] Bedimo AL, Bennett M, Kissinger P, Clark (1998): Understanding barriers to Condom usage among HIV-infected African American Women $J$ Assoc Nurses AIDS 9(3):48-58.

[7] Belachew B.A (2002): Factors affecting accessibility and utilization of Condom in Ethopia Int. Conf. AIDS Jul 7-12; 14

[8] Calazans G, Araujo TW, Venturi G, Franca Junior I. Factors associated with condom use among youth aged 15-24 years in Brazil in 2003. AIDS. 2005; 19(Suppl 4):42-50.

[9] Chimbindi N. Z, McGrath N, Herbst K, San Tint K, Newell M(2010) Socio-Demographic Determinants of Condom Use Among Sexually Active Young Adults in Rural KwaZulu-Natal, South Africa. Open AIDS J. 4:88-95.

[10] Dibua VA, Agweda (2010): Assessing senior secondary school student's knowledge of HIV/AIDS in Nigeria: Implication for counseling. Nigeria Journal of Guidance and counseling 8(4): 233-247.

[11] DKT Ethiopia \& Timset 2009.

[12] Federal Ministry of Health. National HIV Sero-prevalence Sentinel Survey Among Pregnant Women Attending Antenatal Clinics in Nigeria. Abuja Nigeria : Federal Ministry of Health, 2010.

[13] Hassan M, Stockfelt L, Urazahin M, Ahlm C \& Andersson R (2008): HIV/AIDS Awareness and Risk behavior among Students in Semey, Kazakhstan: A cross-sectional Survey BMC International Health \& Human Right. 8:14.

[14] Katikiro E, Njau B (2012): Motivating factors and psychosocial Barriers to Condom use among out-of-school youths in Dar es Salaam, Tanzania: A cross-sectional Survey using the Health Belief Model ISRN AIDS. Article ID 170739 pg.8 
[15] Maticka-Tyndale E. (2012) Condom in sub-saharan Africa. Sex Health; 9(1): 59-72

[16]NACA (2012): Global AIDS response country progress report http://www.unaids.org/en/dataanalysis/knowyourresponse/countryprogressreports/201 2countries/Nigeria\%202012\%20GARPR\%20Report\%20Revised.pdfOlaitan O.L. (2007) Student's knowledge about the meaning of HIV/AIDS. Journal of Physical Education and Research (Joper) vol.8 No 1, pp 1762-1767.

[17] Orubuloye I. O. (2004) Sexual behavior, HIV/AIDS Awareness and condom use among Young people in the Era of HIV/AIDS Epidemic in Nigeria. Paa2004.princeton.edu/papers/41116.

[18] Phillip-Ephraim EE, Gyuse AN, Udonwa NE, Peters EJ, Anyanechi CC (2010): Knowledge and perceptionof HIV prevention through condom use among midlife and Older adults in Calabar, Nigeria. West Indian Med. $j$. vol 59 No 4.

[19] Prata N, Vahidnia F, Fraser A. Gender and relationship differences in condom use among 15-24-year-olds in Angola. Int Fam Plan Perspect. 2005;31:192-9.

[20] UNAIDS, 2012 